\title{
Survey Of Cloud Computing
}

\author{
Amira. A. Elsonbaty \\ High Institute of Engineering \& Technology in New Damietta
}

\begin{abstract}
With expanding volumes of knowledgeable production and the variability of themes and roots, shapes and languages, most detectable issues related to the delivery of storage space for the information and the variety of treatment strategies in addition to the problems related to the flow of information and methods go down and take an interest in the advantage of them face the researchers. In any case, such a great significance comes with a support of a great infrastructure that includes large data centers comprising thousands of server units and other supporting equipment. The cloud is not a small, undeveloped branch of $i t$, it is a type of computing that is based on the internet, an image from the internet. Cloud Computing is a developed technology, cloud computing, possibly offers an overall economic benefit, in that end users shares a large, centrally achieved pool of storing and computing resources, rather than owning and managing their own systems. But, it needs to be environment friendly also. This review paper gives a general overview of cloud computing, also it describes cloud computing, architecture of cloud computing, characteristics of cloud computing, and different services and deployment model of cloud computing. This paper is for anyone who will have recently detected regarding cloud computing and desires to grasp a lot of regarding cloud computing.
\end{abstract}

\section{KEYWORDS}

cloud computing; architecture of cloud computing; characteristics of cloud computing

\section{INTRODUCTION}

Cloud Computing is one of the most popular emerging technologies in today's world. It is a new and promising paradigm which delivers computing as a utility [1]. Cloud computing, which is a another computational model based on grid computing, means storing and accessing data and programs over the internet instead of PC computer's hard drive. Cloud computing is often outlined as a computing surroundings wherever computing wants by one party are often outsourced to a different party and once would like be rise to use the computing power or resources like data or messages, they will get to them by means of the web. It gives different facilitating and conveying administrations over the Internet. It gives the computational assets (Server, Storage, OS and Network) to use as administration, in view of the request of the client. Cloud computing has gained its popularity by providing cheap and easy access to IT (Information Technology). Cloud Computing is today's most emphasized Information and Communications Technology (ICT) paradigm that is directly or indirectly used by almost every online user. Cloud Computing simply means storing and accessing data and programs over the internet instead of computer's hardware. It provides developing environment, ability to manage the resources, application software over the cloud [1]. Business people are drawn towards distributed computing idea as a result of the accompanying resources.

DOI : 10.5121/ijwsc.2018.9402 
- High Speed

- Pay per utilize

- On - Demand self administration

- Location free

- Device free

- Broad Network Access

- Security

- Rapid Elasticity

- Less Capital

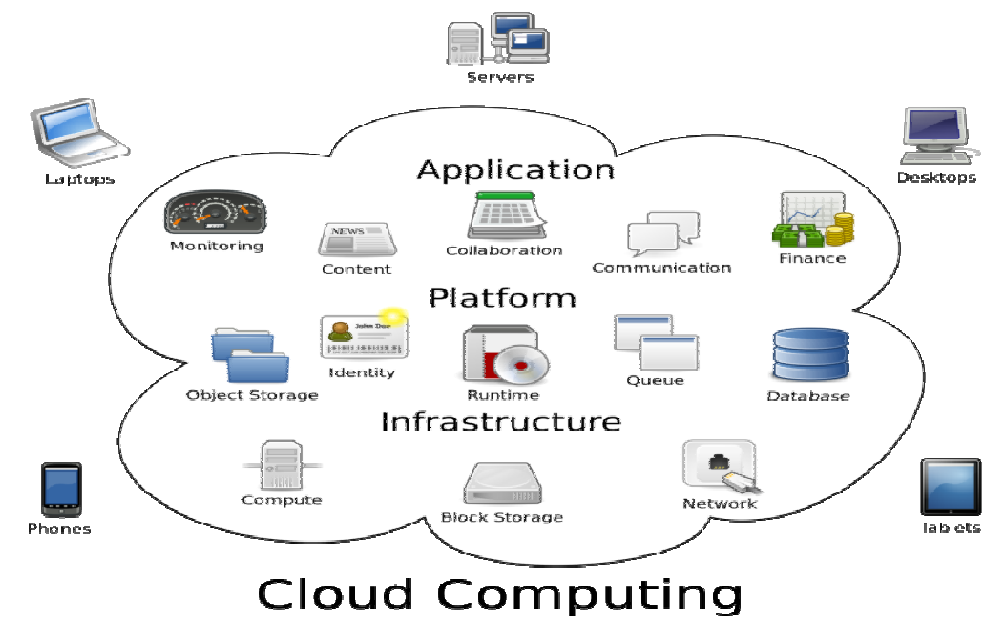

Figure.1. Cloud computing

Cloud computing metaphor: For a user, the network elements representing the provider-rendered services are invisible, as if obscured by a cloud[2]. It offers assets to clients on a compensation as-you-utilize premise. Clients can get to the administrations accessible on the cloud by having a web association. Numerous organizations are conveying administrations from the cloud. A few cases are google, which it has a private cloud that offers online efficiency programming, including email get to, report applications, content interpretations, maps, person to person communication Google+, "Microsoft", which it gives online administration that permits the instruments which are required for business object are moved into the cloud, and Microsoft at present makes its office applications accessible in a cloud which incorporates online capacity, document sharing, web composition and facilitating, and "Salesforce.com" which it enables us to convey progressive client benefit from anyplace, whenever on any gadget.

\section{Cloud Computing Overview}

\subsection{Trends and Definition}


Cloud computing is a general term for the delivery of hosted services over the Internet. Cloud computing empowers organizations to expend Figureuring assets as a utility simply like power instead of building and keep up processing frameworks in-house. In light of the above definitions of the concept of cloud computing technology is evident that it will change the course of dealing with computers where it will be: Your device just transit station for access to the server, which contains storage space enables you to deal with your software. The treatment of your data, and edit your files via the Internet. The possibility of transmission of information in various forms and shares them and interacts with others and through the Internet as well.

Cloud computing promises several attractive benefits for businesses and end users. Three of the main benefits of cloud computing includes:

Self-service provisioning: End users can spin up computing resources for almost any type of workload on-demand.

- Elasticity: Companies can scale up as computing needs increase and then scale down again as demands decrease.

- Pay per use: Computing resources are measured at a granular level, allowing users to pay only for the resources and workloads they use.

It illustrated by the above definitions that cloud computing technology seeks to achieve the following goals

1. Provide storage space for high quality information.

2. Provide access to information and easy retrieval at any time and from any place where the Internet is available.

3. The absence of the need to make backup copies of the information stored on personal computers or external storage devices or flash ROMs and others.

4. Most of the operational availability and application software and free of charge (in most cases), providing the beneficiary cost, time and maintenance.

5. Process share information between beneficiaries and easily traded availability and transmitted via the internet, regardless of the size of that information and forms files.

6. Provides for the possibility of addressing the beneficiary of his information remotely and of the establishment of files or delete or update them, or to determine the levels found in addition to the regulatory measures in the preservation and storage (see Figureure2). 


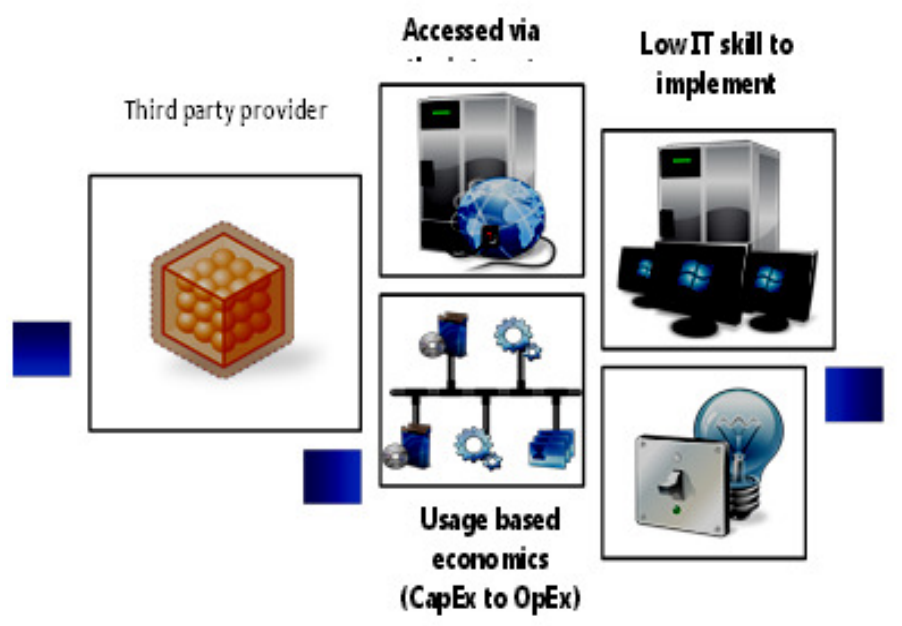

Figure. 2: The cloud is a simple idea, but a more complex entity (cloud platform).

\subsection{Overview Of Existing Concepts For Cloud Structures And Components}

The Cloud computing system can be divided into two sections: the front end and the back end. They each are a unit connected with one another through a network, sometimes the net. Front is what the consumer (user) sees, whereas the rear end is that the cloud of the system. The face has the client's laptop and therefore the application needed to access the cloud and therefore the back has the cloud computing services like numerous computers, servers and information storage [3]. Back end is comprised of the storage servers, virtual machines, security mechanisms. Each of the ends is connected by internet connection.

\section{Architectural Layers Of Cloud Computing}

The architecture of a cloud computing can be categories into four layers: The Physical layer, the infrastructure layer, the platform layer and the application layer, as indicated in Figure3.

The Hardware layer: The hardware layer is responsible for dealing with the physical assets of the cloud, including routers, servers, switches, cooling systems and power.

The Infrastructure layer: The infrastructure layer is also called as virtualization layer. The infrastructure layer makes a pool of storage capacity and computing resources by partitioning the physical resources using virtualization technologies such as KVM and VMware.

The Platform layer: The platform layer based on top of the infrastructure layer, and this layer comprise of operating systems and requisition structures.

The Application layer: The application layer comprises of the actual cloud provisions, for e.g. Business Applications, Multimedia \& Web Services [4].

It is possible to find a number of concepts for Cloud structures in literature. At first sight, these classifications appear to differ from each other to varying extent. Eventually, however, they classify and describe the same phenomenon and share a Menken provides a very detailed concept 
consisting of 7 major components of Cloud Computing, namely application, client, infrastructure, platform, service, storage, and processing power [5].

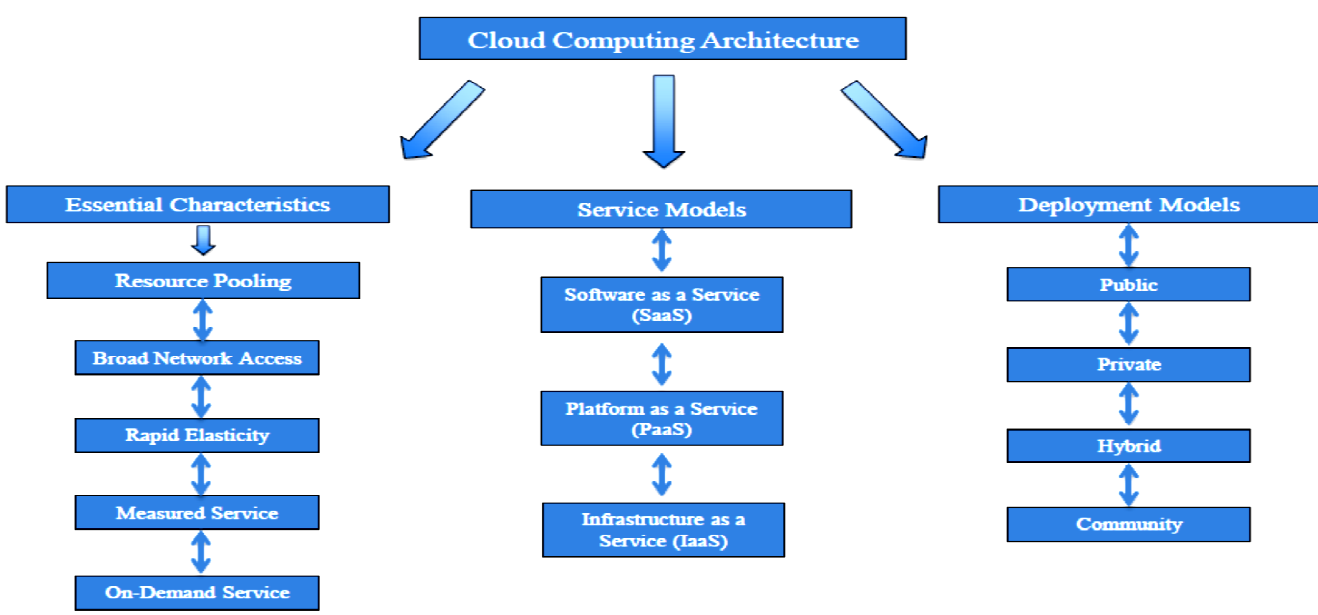

Figure. 3. Cloud computing architecture and general overview.

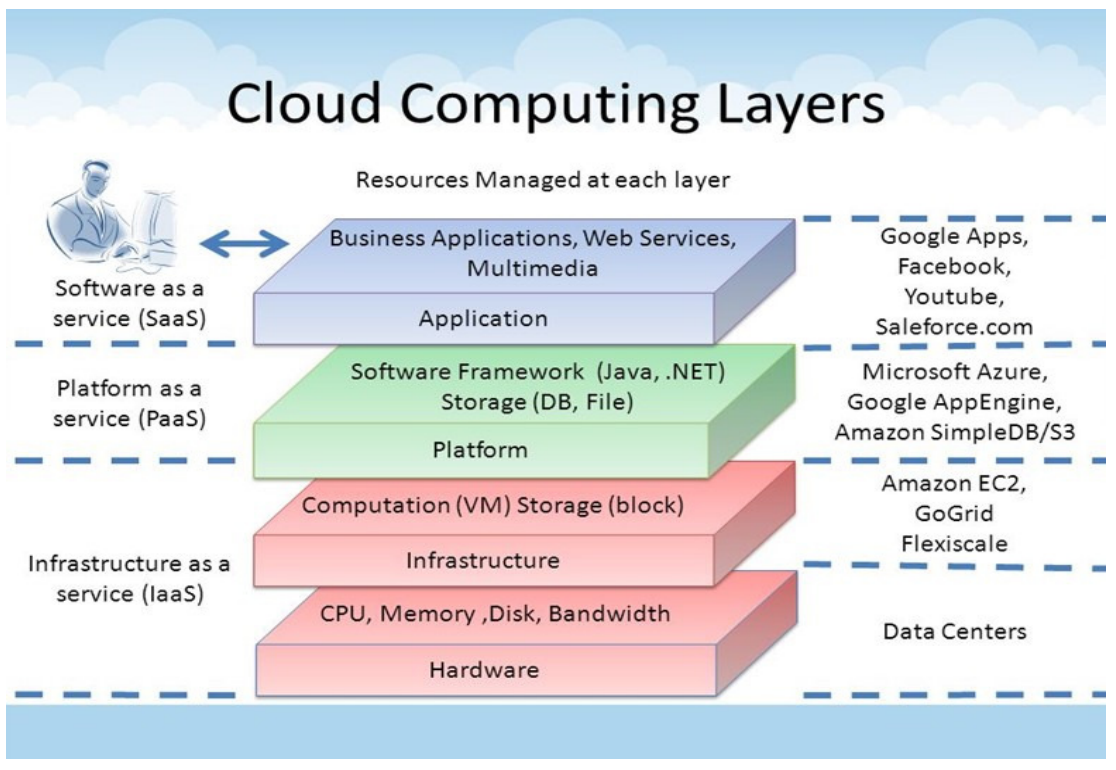

Figure. 4. Architecture layers of cloud computing.

Cloud computing is able to provide a variety of services at the moment, but main three services are Infrastructure-As-A-Service, Platform-As-A-Service and Software-As-A-Service also called as a service model of Cloud computing [6].

There are three types of cloud services provided by cloud for subscription: Software as a Service (SaaS), Platform as a Service (PaaS), and Infrastructure as a Service (IaaS). These three types 
provide different services for the cloud. Choose the provider according to the needs and services provided.

Software as a Service: SaaS is a software delivery method which provides access to applications hosted by a service provider. Users no need to license the software and don't need to invest in hardware Examples of SaaS providers include Salesforce.com[7].

Cloud Infrastructure as a Service, or IaaS - where the capability provided to the customer is to provision processing, storage, networks, and other fundamental computing resources where the customer is able to deploy and run arbitrary software, which can include operating systems and applications. The customer does not manage or control the underlying cloud infrastructure but has control over operating systems, storage, deployed applications, and possibly limited control of select networking components such as firewalls.

Cloud Platform as a Service, or PaaS - where the capability provided to the customer is to deploy onto the cloud infrastructure, customer-created or acquired applications created using programming languages and tools supported by the provider. The customer does not manage or control the underlying cloud infrastructure, including network, servers, operating systems, or storage, but has control over the deployed applications and possibly application hosting environment con Figureurations.

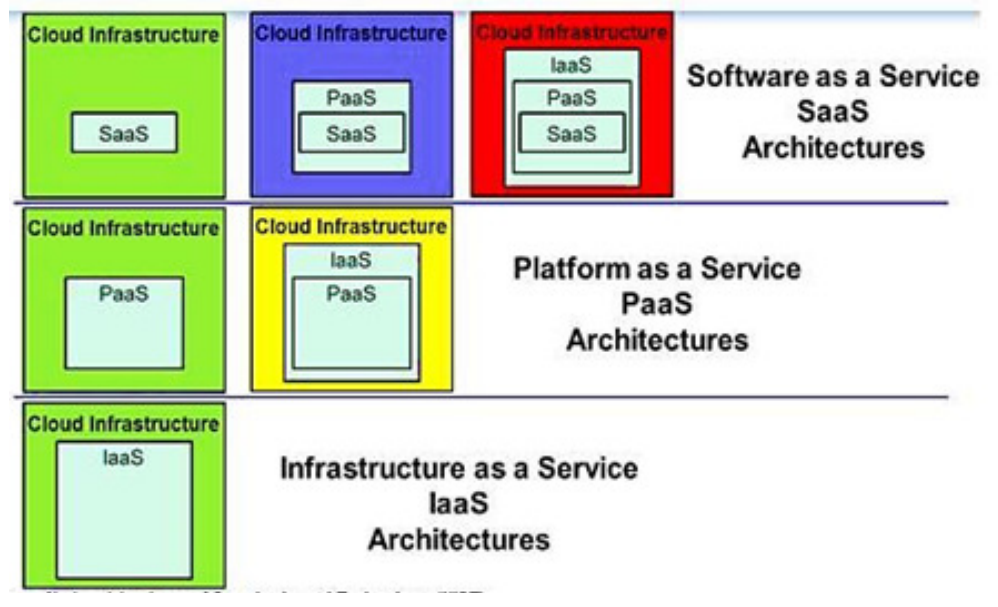

Figure. 5. Service model of Cloud computing 


SaaS
$\begin{gathered}\text { Software as a } \\ \text { Service }\end{gathered}$

\section{Classification Of Clouds}

Figure. 6. Cloud computing levels

Clouds can generally be classified according to who the owner of the Cloud data centers is. A Cloud environment can comprise either a single Cloud or multiple Clouds. Thus, it can be distinguished between single-Cloud environments and multiple-Cloud environments. The following subsections provide a classification of single-Cloud environments according to the Cloud data center ownership and a classification of multiple-Cloud environments according to which type of Clouds is combined. Cloud Computing solutions are deployed in one of four models:

A Private Cloud - where the cloud infrastructure is operated solely for an organization. It may be managed by the organization or a third party and may exist on-premise or off-premise.

A Public Cloud - where the cloud infrastructure is made available to the general public or a large industry group and is owned by an organization selling cloud services.

A Community Cloud - where the cloud infrastructure is shared by several organizations and supports a specific community that has shared concerns such as mission, security requirements, policy, and compliance considerations. It may be managed by the organizations or a third party and may exist on-premise or off-premise.

A Hybrid Cloud - where the cloud infrastructure is composed of two or more clouds; such as a private cloud and a community or public cloud, that remain unique entities but are bound together by standardized or proprietary technology that enables data and application portability such as cloud bursting for load-balancing between clouds. 


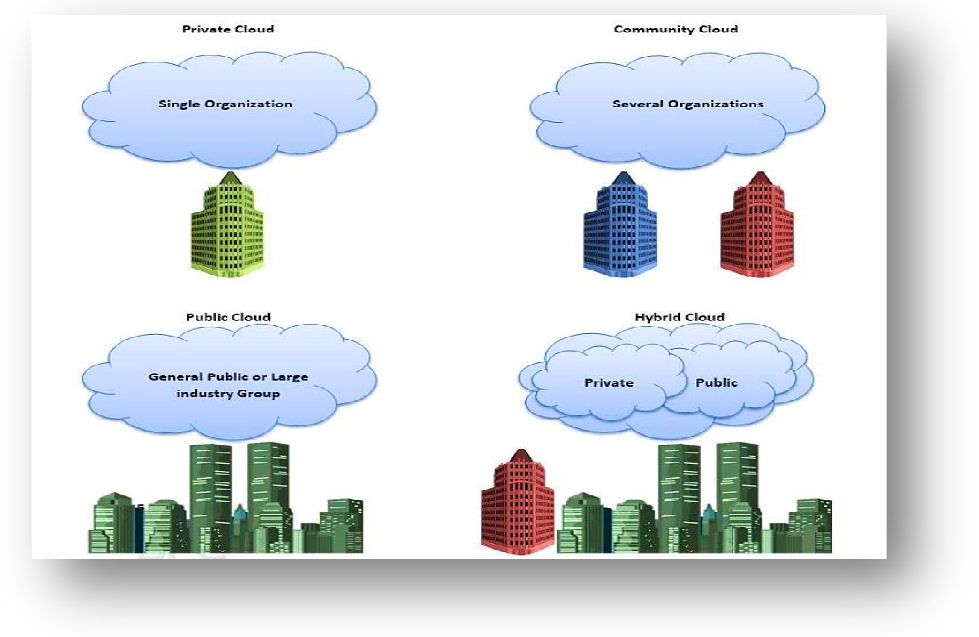

Figure.7.Classification of clouds

The Table.1. Shows the features and challenges of cloud computing services models [8-9-10-11].

\begin{tabular}{|c|c|c|}
\hline Challenges & Features & $\begin{array}{l}\text { Attribute } \\
\text { system }\end{array}$ \\
\hline $\begin{array}{l}\text { 1. Temperature of cloud places need to be maintained } \\
\text { 2. System should be power failure tolerant } \\
\text { 3. Selection of infrastructure hardware is very } \\
\text { important } \\
\text { 4. Connection betweencloud and hardware should be } \\
\text { a high bandwidth channel } \\
\text { 5. Storage of cloud should be able to fulfill the } \\
\text { changing demands of large data size } \\
\text { 6. Loss of control }\end{array}$ & $\begin{array}{l}\text { 1. Elasticity } \\
\text { 2. Transfering the risks } \\
\text { 3. Reduced operational } \\
\text { costs } \\
\text { 4. Availability of latest } \\
\text { infrastructure } \\
\text { 5. Inter-operatability } \\
\text { 6. Disaster recovery }\end{array}$ & 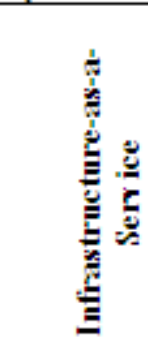 \\
\hline $\begin{array}{l}\text { 1. Data security is highly preferred feature } \\
\text { 2. High availability requirement } \\
\text { 3. Authentication and authorization } \\
\text { 4. Data integrity } \\
\text { 5. Data privacy } \\
\text { 6. Network security } \\
\text { 7. Cloud standardization } \\
\text { 8. Deployment of cloud resources in different } \\
\text { countries results in conflict of rules } \\
\text { 9. Data backup } \\
\text { 10. Web application security } \\
\text { 11. Data confidentiality } \\
\text { 12. Virtualization }\end{array}$ & $\begin{array}{l}\text { 1. Cost minimization } \\
\text { 2. High throughput } \\
\text { 3. Time saving } \\
\text { 4. Availability of high tech } \\
\text { services } \\
\text { 5. High availability } \\
\text { 6. Reduced administration } \\
\text { cost }\end{array}$ & 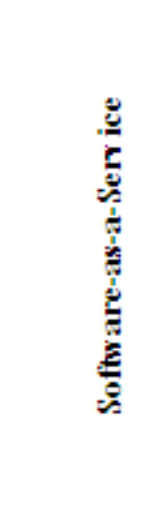 \\
\hline $\begin{array}{l}\text { 1. Limited APIs } \\
\text { 2. Data Lock-in } \\
\text { 3. Auditability } \\
\text { 4. Performance is unpredictable } \\
\text { 5. Lack of control over low level security } \\
\text { 6. Data inaccessibility between applications } \\
\text { 7. Vulnerabilities of web applications and SOA }\end{array}$ & $\begin{array}{l}\text { 1. Access of high level } \\
\text { infrastructure } \\
\text { 2. Fexibility } \\
\text { 3. Ready to use services } \\
\text { 4. Scalability } \\
\text { 5. Less a dministration cost }\end{array}$ & 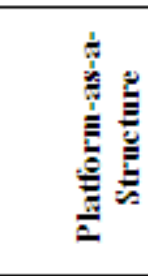 \\
\hline
\end{tabular}




\section{Basic Characteristics Of Cloud Computing}

To serve the cloud computing a set of characteristics those distinguish them from traditional hosting and are:

Self-service on-demand self-service: The consumer can unilaterally provision computing capabilities, such as server time and network storage, as needed automatically without requiring human interaction with each provider cheek.

Network Access Capabilities are available across the network and accessed through standard mechanisms that promote use by thin or rich client platforms Heterogeneous. Examples include cell phones, computers and suggestive tablets and laptops, and workstations. Therefore, flexible service -hat could be available to the user much or as little service as he pleases, at any given time.

Resource Pack Resource pooling. It has grouped cloud computing resources to serve many consumers using a multi-tenant model multi-tenant model with different physical and virtual resources dynamically allocated and re- allocated according to the consumer's request.

There is a sense of independence of the site from where it is not the customer has no control or knowledge of the site the exact sources provided, but be able to determine the location at the highest level of abstraction (abstraction) For example, (the state, or the state, or the Information Center data center).

Examples of resources are storage, processing, memory, and the bandwidth of the network. The cloud service is fully managed by the service provider, not the consumer needs only a PC and Internet access.

Flexibility Rapid elasticity. It can be conditional capacity released flexibly in some cases automatically, to expand the scope of input and output quickly and in line with demand. For the consumer, it is often available capacity for the supply seems to be unlimited and can be relied upon in any amount and at any time.

Measurement service measured service. Controlled and the pride of the cloud systems automatically uses of resources by taking advantage of the ability to measure metering certain level of appropriate abstraction to the type of service and payment for as little or as much as you need the library or organization (e.g., storage, processing, bandwidth, and the accounts of active beneficiary). It can monitor the use of controlled resources and maintained, providing transparency for both the supplier and the consumer alike used the service consumer.

In cloud computing, users access the information, applications or the other services with the assistance of a browser not with standing the device used and also the user's location. The infrastructure that is mostly provided by a third-party is accessed with the assistance of the web. Price is reduced to a major level because the infrastructure is provided by a third-party. Less IT skills are needed for implementation. Reliable services are often obtained by the employment of multiple sites that is appropriate for business continuity and disaster recovery. Sharing of resources and prices amongst an outsized assortment of users permits economical utilization of the infrastructure. Maintenance is simpler just in case of cloud computing applications as they have not been put in on every user's PC. 
Pay per use facility permits activity the usage of application per shopper on regular bases. Performance is often monitored and so it's ascendible. Security is often pretty much as good as or higher than ancient systems as a result of suppliers are able to devote resources to resolve security problems that several customers cannot afford. However, security still remains a crucial concern once the information is sort of confidential [12].

The cloud could be a massive resource pool that you just should buy in keeping with your need; cloud is simply like running water, electric, and gas which will be charged by the quantity that you just used. Cloud computing makes user get service any place, through any reasonably terminal. The resources it needed return from the cloud rather than visible entity. Users will attain or share it safely through a simple method, anytime, anywhere. Users will complete a task that can't be completed in an exceedingly single personal computer [13].

According to usage of assets and control of substructure, there are three types of PaaS shareholders [14].

\section{PaaS Hoster}

PaaS hoster is responsible for deploying hardware infrastructure through IaaS, Which are necessary for accomplishing user demands.

\section{PaaS Provider}

PaaS provider is responsible for providing a growth platform to designers so they can work on their web application development without having knowledge about servers and front end applications.

\section{PaaS User}

PaaS user is the developer, who will develop applications. They must have a browser based utility to work on that platform. They will pay for service area as much they use

\section{Challenges Of Cloud Computing}

Top five challenges Of cloud computing, hence cloud computing challenges have always been there.

Companies are increasingly aware of the business value that cloud computing brings and are taking steps towards transition to the cloud. A smooth transition entails a thorough understanding of the benefits as well as the challenges involved. Like any new technology, the adoption of cloud computing is not free from issues. Some of the most important challenges are as follows.

Security and Privacy: The main challenge to cloud computing is how it addresses the security and privacy concerns of businesses thinking of adopting it. The fact that the valuable enterprise data will reside outside the corporate firewall raises serious concerns. Hacking and various attacks to cloud infrastructure would affect multiple clients even if only one site is attacked.

These risks can be mitigated by using security applications, encrypted file systems, data loss software, and buying security hardware to track unusual behavior across servers. It is difficult to assess the costs involved due to the on-demand nature of the services. Budgeting and assessment of the cost will be very difficult unless the provider has some good and comparable benchmarks 
to offer. The service-level agreements (SLAs) of the provider are not adequate to guarantee the availability and scalability. Businesses will be reluctant to switch to cloud without a strong service quality guarantee.

Interoperability and Portability. Businesses should have the leverage of migrating in and out of the cloud and switching providers whenever they want, and there should be no lock-in period. Cloud computing services should have the capability to integrate smoothly with the on-premise IT.

Reliability and Availability: Cloud providers still lack round-the-clock service; this results in frequent outages. It is important to monitor the service being provided using internal or thirdparty tools. It is vital to have plans to supervise usage, SLAs, performance, robustness, and business depend on these services.

Performance and Bandwidth Cost: Businesses can save money on hardware but they have to spend more for the bandwidth. This can be a low cost for smaller applications, but can be significantly higher for the data-intensive applications. Delivering intensive and complex data over the network requires sufficient bandwidth. Because of this, many businesses wait for a reduced cost before switching to the cloud.

All these challenges should not be considered as roadblocks in the pursuit of cloud computing. It is rather important to give serious consideration to these issues and the possible ways out before adopting the technology.

\section{CONClusion}

Cloud computing is a new technology wide studied in recent years. Currently there are several cloud platforms that are employed in each in trade and in educational. The way to use these platforms could be a huge issue.

During this paper, we have a tendency to delineate the definition, styles, and characteristics of cloud computing, cloud computing services, readying model and challenges of cloud computing. Cloud computing is an emerging technology which introduced itself as a service oriented technology. It is working on the principle of on demand service and scalability. It is providing services in many ways, including software, platform and infrastructure, making the users free of installing and administering these services.

In spite the fact that cloud computing provides high performance, high availability, fault tolerant services; the issues it comes with are also very serious in nature.

Of the worth mentioning are data and network security, data authenticity and audit ability, lack of user control over data and security polices and virtualization problem. In order to attract the organizations and build the confidence of customers, these issues need to be well researched and resolved.

To summarize, the cloud provides many services for computer user as well as large and small organizations. It covers an area of computing to a broader range and increases the ease of use by just having access through any internet connection. However, despite of this it also has some weak area to work upon. If we want to use the services of the cloud, We should choose the type 
International Journal on Web Service Computing (IJWSC), Vol.9, No.3/4, December 2018

of cloud and the type of provider according to our needs that will be most useful to us.also check for the methods provided for the security purpose and saving energy and cost.

\section{FUTUE WORK}

Cloud computing is Built on a pay-as-you-go model, it permits hosting of universal applications from customer, scientific, and business areas. But, data centers, hosting Cloud applications consume massive amounts of energy, paying to high operational costs and carbon footprints to the environment. Green cloud Computing is the future technology that cares environment, recycle consumed power and energy, and enhance the resources efficiently. Green computing makes IT industry environment friendly. As we are moving towards cloud and using its application in every. Therefore, we want Green Cloud computing solutions that can not only save energy for the environment but also reduce operational costs. Therefore, Next research will focus on the green cloud and how to use it in different fields.

\section{REFERENCES}

[1] Bharti Wadhwa, "Energy Saving Approaches for Green Cloud Computing: A Review", Proceedings of 2014 RAECS UIET Panjab University Chandigarh, 06 - 08 March, 2014 978-1-4799-22918/14/\$31.00 @2014 IEEE

[2] Jasleen Kaur, Ms. Anupma Sehrawat, Ms. Neha Bishnoi, " Survey Paper on Basics of Cloud Computing and Data Security," International Journal of Computer Science Trends and Technology (IJCST) - Volume 2 Issue 3, May-Jun 2014.

[3] https://en.wikipedia.org/wiki/Cloud_computing,12-9-4:30pm.

[4] Yashpalsinh Jadeja, Kirit Modi, "Cloud Computing - Concepts, Architecture and Challenges" in Proceeding of International Conference on Computing, Electronics and Electrical Technologies [ICCEET], 2012.

[5] Qi Zhang, Lu Cheng and Raouf Boutaba, "Cloud computing: state-of-the-art and research challenges”. Journal of Internet Services and Applications, Volume 1, Issue 1, pp 7-18, May 2010

[6] Ivanka Menken," Cloud Computing - The Complete Cornerstone Guide to Cloud Computing Best Practices Concepts, Terms, and Techniques for Successfully Planning, Implementing ... Enterprise IT Cloud ComputingTechnology", London, UK, UK @2008 , ISBN:1921573007 9781921573002,2008.

[7] Ms. Disha H. Parekh, Dr. R. Sridaran, "An Analysis of Security Challenges in Cloud Computing," (IJACSA) International Journal of Advanced Computer Science and Applications, Vol. 4, No.1, 2013.

[8] Jasleen Kaur, Ms.Anupma Sehrawat, Ms.Neha Bishnoi ,"Survey Paper on Basics of Cloud Computing and Data Security", International Journal of Computer Science Trends and Technology (IJCST) - Volume 2 Issue 3, May-Jun 2014.

[9] M. Armbrust, O. Fox, R. Griffith, A. D. Joseph, Y. Katz, A. Konwinski, et al., "M.: Above the clouds: A Berkeley view of cloud computing," 2009.

[10] S. Subashini and V. Kavitha, "A survey on security issues in service delivery models of cloud computing," Journal of Network and Computer Applications, vol. 34, pp. 1-11, 2011. 
International Journal on Web Service Computing (IJWSC), Vol.9, No.3/4, December 2018

[11] Aniruddha S. Rumale, D.N.Chaudhari, " Cloud Computing: Infrastructure as a Service," International Journal of Inventive Engineering and Sciences (IJIES) ISSN: 2319-9598, Volume-1, Issue-3, February 2013.

[12] Imran Ashrafa, "An Overview of Service Models of Cloud Computing," International Journal of Multidisciplinary and Current Research 27 Aug 2014, Vol.2 [8] Yashpalsinh Jadeja; Kirit Modi, "Cloud Computing - Concepts, Architecture and Challenges" in Proceeding of International Conference on Computing, Electronics and Electrical Technologies [ICCEET], 2012.

13] Xu Wang, Beizhan Wang, Jing Huang, "Cloud computing and its key techniques" in Proceeding of IEEE Conference, 2011.

[14] Michael Boniface, Bassem Nasser, Juri Papay, Stephen C. Phillips, Arturo Servin, Xiaoyu Yang, Zlatko Zlatev, Spyridon V. Gogouvitis, Gregory Katsaros, Kleopatra Konstanteli, George Kousiouris, Andreas Menychtas, Dimosthenis Kyriazis, "Platform-as-a-Service Architecture for Real-time Quality of Service Management in Clouds," Fifth International Conference on Internet and Web Applications and Services, 2010. 